\title{
Hacia la recuperación económica y la equidad social
}

\section{ESTA CRISIS Y LA DE LOS AÑOS TREINTA}

Comparada con la depresión mundial de los años treinta, esta crisis mundial es mucho más compleja y difícil de atacar, así como grave su incidencia sobre la América Latina. Ante muy difíciles circunstancias exteriores, hubo entonces que dar gran impulso a la industrialización. La experiencia era incipiente en esta materia. Se habian segado las fuentes de capital externo, y prevalecía la noción del Estado prescindente. $\mathrm{X}$, sin embargo, gracias a medidas de emergencia, la América Latina pudo crecer en aquellos años treinta con ritmo más intenso que el de sus menguadas exportaciones primarias. Supo recuperarse e iniciar una nueva etapa en su desarrollo, basada en la progresiva dilatación del mercado interno. Frente a la adversidad externa, los países latinoamericanos se encontraron a sí mismos.

\section{LA GRISIS EN LOS GENTROS}

Ahora, como entonces, el origen de la crisis está en los centros, principalmente en los Estados Unidos, donde venía incubándose antes del alza del petróleo, que le imprime aún más intensidad. Cunde el desconcierto después de largos años de prosperidad, interrumpidos en la primera mitad de los setenta, años en los cuales se había alcanzado un pujante dinamismo.

Sostengo que la crisis venía incubándose en los Estados Unidos de tiempo atrás porque, a mi juicio, esa gran prosperidad generó una tendencia al desequilibrio estructural entre el ritmo de consumo y el ritmo de acumulación de capital reproductivo, o sea, el capital que multiplica el empleo y la productividad. Allí está el origen principal de la inflación. De todos modos, el ritmo de la productividar ha descendido, lo cual a su vez ha debilitado el ritmo de acumulación reproductiva. Todo ello, sin excluir otros factores.

Ese desequilibrio estructural se ha agravado con una de sus más notorias expresiones: el desequilibrio del presupuesto, tanto por los 
gastos sociales (consumo social), como por los gastos militares (consumo militar).

Como quiera que fuere, resulta contraproducente tratar el fenómeno inflacionario con una restricción monetaria acompañada de elevadísimas tasas de interés. Pues sobreviene entonces un ingente desperdicio de recursos productivos y se agudiza el desempleo. Además de acentuar la inestabilidad de los tipos de cambio, con tan serias consecuencias internacionales.

Sobre ser económicamente contraproducente, este sacrificio social es inaceptable en los tiempos que corren. Pues recae principalmenmente sobre los elementos más débiles del sistema, asi sea dentro de los propios centros como en la periferia. En lo que a ésta atañe, acaba de reafirmarlo una fuente muy autorizada: "... un tercio o más del descenso de la inflación podría atribuirse a la debilidad de los precios de los productos primarios, los cuales es de esperar que puedan recobrar lo perdido en la eventualidad de un repunte de las actividades".

Este repunte de las actividades parecería haberse iniciado en aquel país. Pero se duda que pueda adquirir suficiente intensidad y persistencia, y se teme que la expansión crediticia traiga consigo un nuevo ciclo inflacionario. Se trata, a mi juicio, de un temor justificado, pues el sistema, por su propia evolución estructural, ha quedado expuesto a sucesivos ciclos de esta naturaleza, que persistirán mientras no se ataque la tendencia al desequilibrio estructural entre los ritmos de consumo y acumulación reproductiva. Tiene que tenerlo bien presente la América Latina.

Es notorio que el receso ha traído un recrudecimiento de las medidas proteccionistas y discriminatorias en sus más variadas formas. El GATT se ha vuelto impotente para contenerlas. La economía mundial tiende a fragmentarse, como sucedió en la Gran Depresión, cuando la violenta contracción en los Estados Unidos y la intensa elevación de sus aranceles, propagaron este proceso al resto del mundo, rompiendo el régimen multilateral de comercio y pagos.

\section{LA REGUPERAGIÓN}

Se reconoce en todas partes la urgencia de hacer frente al peligro que todo esto significa con una política de recuperación coordinada entre los países desarrollados. Es imprescindible la iniciativa de los Estados Únidos que, hoy como entonces, constituyen el epicentro de esta crisis.

La urgencia de promover la recuperación es también notoria en nuestros países, $y$ no hay que postergarla hasta que los centros la emprendan y ella alcance amplitud. A pesar de grandes obstáculos,

IOECD Economic Outlook, No 32, Paris, 17 December 1982. 
es indispensable impulsarla también entre nosotros, a fin de contrarrestar el desempleo y el descenso en el nivel de vida en que se manifiesta el serio encogimiento del mercado interno.

Para alentarla con fuerte impulso se requiere una cautelosa expansión crediticia acompañada de un franco descenso en las tasas de interés y de una severa disciplina bancaria. Pero habrá que prevenir a tiempo ciertas consecuencias externas e internas que podrian llevar al fracaso de esta política.

En cuanto a lo externo, la expansión acrecentará la demanda de importaciones y será necesario someter a éstas, no obstante el descenso que ya han sufrido, a cierto rigor selectivo en la medida en que sean insuficientes las exportaciones y continúe el deterioro de los términos del intercambio, mientras se elevan los pesados servicios de la deuda externa.

La restricción de las importaciones está en marcha. $Y$ junto a sus resultados positivos hay que lamentar el retroceso que ha traido en el intercambio recíproco. Para que no se agudice este problema se está volviendo al bilateralismo, como sucedió en la Gran Depresión mundial. A pesar de los inconvenientes que el mismo trae consigo, es preferible mantener de esta manera el intercambio recíproco antes que continuar reduciéndolo.

Sería un gran error perder de vista la importancia del comercio recíproco entre nuestros países al aplicarse medidas selectivas de importación. Es cierto que son medidas de emergencia y no de índole estructural. Pero sì no se excluye de las restricciones selectivas de importación a los países latinoamericanos, se perdería gran parte o todo de lo que ya se había logrado, lo cual haría más difícil en el futuro el reajuste estructural del intercambio.

El régimen de pagos compensados multilateralmente, que ya se ha iniciado en forma modesta pero con éxito, debiera extenderse, tanto en la duración como en las dimensiones de los créditos recíprocos, a fin de ayudar a estas medidas de emergencia. Todo ello con vistas a una futura unión de pagos latinoamericanos cuyas posibilidades habría que examinar en conjunción con la reforma monetaria internacional.

Por otro lado, será necesario dosificar las remesas de utilidades al exterior y contrarrestar el éxodo de recursos. En algunos casos, ha de presentarse un serio dilema: continuar con una restricción monetaria y elevadas tasas de interés con muy graves consecuencias sociales y políticas, o atacar el desempleo con medidas expansivas que podrían exigir un control temporal del movimiento de fondos con el exterior, a pesar de los conocidos inconvenientes que le acompañan. Inconvenientes que se acentúan en algunos casos, porque la inflación y las elevadas tasas de interés han traído consigo una verdadera hipertrofia de depósitos bancarios dispuestos a salir al exterior si se bajan intensamente las tasas internas, como convie- 
ne hacerlo. No hay que excluir la aplicación de medidas heroicas en tales casos.

Es claro que estas medidas de emergencia podrian aliviarse hasta desaparecer conforme se desenvuelva la recuperación de los centros; como que esas medidas no provienen de preferencias doctrinarias sino de exigencias reales y concretas de la realidad.

Hay quienes preconizan la contracción de la actividad interna a fin de reducir las importaciones y las remesas al exterior hasta conseguir el equilibrio. Mal podría seguirse un consejo semejante frente a la necesidad de reactivación.

\section{REGUPERAGIÓN Y RIESGO INELACIONARIO}

En lo interno, no cabe negar el riesgo inflacionario de una política expansiva, sobre todo si al desenvolverse la recuperación no se toman medidas para corregir el déficit del sector público. Si se tomaran estas medidas antes de lograr los grandes efectos positivos de aquella, agravarian generalmente el desempleo, en tanto que después serían necesarias para coadyuvar a la contención de las consecuencias inflacionarias.

Sobre este punto de tanta significación cabe una definición previa y categórica. Si es inadmisible hacer recaer sobre la gran masa de la población el costo social de medidas antinflacionarias, también lo es en cuanto al costo social de la recuperación.

Hay pues que inspirarse en una nueva concepción de la política de ingresos. Desde luego, una elevación prudente de remuneraciones generalmente deprimidas podrá ser un elemento positivo de reactivación de la demanda. ¿Qué hacer, sin embargo, frente a un alza ulterior de los precios debido a esta reactivación?

Por mucho que hubiere capacidad ociosa, el alza, dentro de ciertos límites, no solamente es inevitable sino conveniente, a fin de restablecer las ganancias de las empresas y la capacidad de acumulación de capital. Ello, sin embargo, plantea una opción sociopolítica insoslayable. Si se elevan nuevamente las remuneraciones, el aumento resultante en los costos acentuará fatalmente la espiral inflacionaria en vez de contenerla. $Y$ si se frenan las remuneraciones, tendrá que acudirse -en compensación - a los resultados financieros de las empresas, habida cuenta de la necesidad de acrecentar la acumulación de capital, en la cual cabría la participación, en una u otra forma, de la fuerza de trabajo. A la luz de una larga y perturbadora experiencia, el propósito de mejorar el nivel de vida con expedientes inflacionarios ha probado ser una peligrosa ilusión. Se impone pues inventar fórmulas innovadoras combinando el vigor del desarrollo con la equidad distributiva. En otros términos, fórmulas que aseguren la participación de la fuerza de trabajo en el fruto de la reactivación a medida que esta se desenvuelva, pero sin elevar los costos de producción. 
Corresponde a esta altura una reflexión importante sobre las formas de austeridad. Es necesario distinguir entre la austeridad que se preconiza para corregir antisocialmente la inflación mediante la restricción crediticia y la austeridad que debiera acompañar una política de recuperación. Tendrá en este caso que limitarse el ritmo del consumo, o el mismo consumo, a fin de acumular más capital reproductivo y acrecentar el empleo y la productividad más allá de lo que podría conseguirse con la utilización de la capacidad productiva ociosa. Pero esto no significa restricción del consumo global, sino cambio en la composición social del consumo: incidir en el consumo de los más favorecidos en la distribución del ingreso para aumentar el de los menos favorecidos mediante el mayor empleo y los mayores ingresos que la acumulación trae consigo. He ahí la significación dinámica de la austeridad, no sólo en los gastos privados (sobre todo en la sociedad privilegiada de consumo) sino también en los gastos desproporcionados del Estado. La racionalidad de estas medidas tiene también que combinarse con su equidad.

\section{LA DEUDA EXTERNA}

Hay que ser conscientes del marco más o menos estrecho en que han de desenvolverse las medidas de recuperación, frente al intenso menoscabo de la capacidad de pagos exteriores de nuestros países, $\mathrm{Y}$ si a ello se agrega el peso de la deuda externa, podrá llegarse a muy graves estrangulamientos de índole exterior. Los arreglos recientes de la deuda externa han conjurado un desastre financiero, pero se está aún muy lejos de haber resuelto el problema.

Difícilmente habrá país alguno que acepte comprimir al extremo su actividad económica y sus importaciones ineludibles a fin de hacer frente a los pesados servicios de su deuda externa. Es de elemental prudencia prevenir esta grave situación en los países deudores. $\mathrm{Y}$ como no podría seguirse por mucho tiempo tomando nuevos créditos para pagar elevadísimos intereses, habrá que alargar holgadamente los plazos y reducir los intereses a cifras razonables. Esos arreglos recientes han pospuesto un problema que no tardará en presentarse de nuevo. Es de elemental previsión que los gobiernos de los países deudores y acreedores negocien fórmulas adecuadas, sin esperar un desenlace crítico de muy serias repercusiones en el curso de la recuperación.

Nadie discute ahora que todo ello es resultado de la licencia que ha imperado en el mercado de eurodólares: El incentivo de ganancias en el juego del mercado ha sido un elemento primordial en la dinámica del sistema. Pero el incentivo de ganancias en la creación bancaria de dinero conduce a la inflación: Es muy diferente pro- 
ducir bienes que producir dinero discrecionalmente: Tal es el sentido de la regulación monetaria en donde debe manifestarse la prudencia de los bancos centrales. Sin embargo, las operaciones de crédito en el mercado de eurodólares, impulsadas por aquel incentivo, escaparon a toda regulación tanto en la creación monetaria adicional que allí se opera como en la inmoderada concesión de préstamos, sin condicionalidad alguna. La condicionalidad es indispensable; pero hay que reconocer que la del FMr no ha considerado debidamente las exigencias del desarrollo de los países periféricos. Es indispensable formular nuevos principios que impriman más eficacia a la acción reguladora del FMr.

Huelga insistir sobre las consecuencias de esta desorbitación crediticia en el plano mundial. La necesidad de esos nuevos principios deberá ser punto importante en la reforma del sistema monetario internacional.

Es aconsejable que nuestros países aborden a tiempo esta reforma para no estar desprevenidos y hacer gravitar sus legítimos intereses. A la luz de la experiencia pasada, la creación internacional de dinero tiene que ser obra de decisión colectiva y no de un solo país, por poderoso que fuere. M̀ás aún, es esencial que esta reforma vaya acompañada de nuevos principios antinflacionarios, tanto en el plano interno como en el internacional, puesto que la política monetaria ha probado ser contraproducente. Volveria a ser eficaz si se transformara el proceso de distribución y acumulación donde radica el principal origen de la inflación. De no ser así, se correría el riesgo de una nueva inflación generalizada.

\section{LA COOPERAGIÓN FINANGIERA EN CAMBIOS ESTRUCTURALES}

El estiramiento de los plazos de la deuda y la rebaja de intereses, indispensable como es a fin de aliviar el desequilibrio exterior, no sería suficiente para alentar una política de recuperación económica en nuestros países. Por más que puedan acrecentarse los recursos internos de acumulación de capital, ese desequilibrio hará difícil transferir parte de los recursos internos de ahorro a fin de adquirir bienes de capital en los centros. En la recuperación se necesitará la aportación financiera internacional.

Mientras tanto, conviene examinar la conveniencia de crear nuevos derechos especiales de giro, sin perjuicio de la ampliación de las cuotas del Fondo Monetario Internacional. La astringencia presente en la liquidez internacional parecería señalar la necesidad de este alivio monetario: Sería el momento de insistir en el vínculo entre ello y el financiamiento del desarrollo. Las dimensiones de esta operación tienen que determinarse, sin embargo, de acuerdo con las exigencias del intercambio mundial y no con las del financiamiento: éste sería sólo un subproducto de aquél. 
Por otro lado, ha de recordarse que tanto el Banco Mundial como el FMI reconocieron no hace mucho tiempo la necesidad de apoyar cambios estructurales para ayudar a corregir la tendencia al desequilibrio exterior, además de los factores coyunturales que lo acentúan. Es de esperar que cooperen eficazmente en este aspecto de la recuperación, que, por cierto, colinda con una política de más largo aliento. En fin de cuentas, el largo plazo comienza en el momento presente.

\section{LA TRANSFORMACIÓN DEL INTERCAMBIO}

Estos cambios estructurales atañen, desde luego, a la estructura productiva interna, que deberá orientarse tanto hacia las exportaciones de manufacturas (además de las de productos primarios) como a la producción para el mercado interno mediante una sustitución de importaciones basada principalmente en el comercio recíproco entre los países latinoamericanos.

Este no es tampoco asunto de preferencias doctrinarias. Todo indica, en efecto, que durante este decenio la tasa de desarrollo de los centros será muy inferior a la de los tiempos de prosperidad. En tales tiempos, los centros liberalizaron intensamente su comercio entre ellos, pero no lo hicieron en medida comparable con los pafses periféricos. Al contrario, mantuvieron su proteccionismo inveterado.

Esta dualidad de tratamiento se debe primordialmente a la diná mica misma de los centros. En efecto, buena parte del ingreso proveniente del aumento de productividad se ha traducido en demanda de bienes de servicios que se diversifican continuamente en virtud de innovaciones tecnológicas que las transnacionales han aprovechado intensamente: La liberalización del intercambio se ha dado notablemente en esos bienes y la periferia apenas ha participado en ello, lo mismo que en otros tiempos en que había quedad.o excluida del proceso de industrialización. En cambio nuestros países han demostrado su creciente capacidad exportadora de bienes menos avanzados, cuyo consumo tiende a subir con mucho menor intensidad que en aquellos otros bienes favorecidos por el intercambio. Allí no ha habido liberalización aún en los tiempos de prosperidad de los centros. $\mathrm{Y}$ el receso ha multiplicado restricciones de toda indole.

Independientemente del receso, se trata de un serio problema estructural que los centros están muy lejos de haber afrontado con una visión de ventajas recíprocas. Trataré de explicarlo.

La competencia entre los centros en aquellos bienes diversificados no se ha traducido generalmente en baja de precios, sino en nuevas modalidades o nuevos bienes. $\mathrm{Y}$ el aumento de productividad, además de estimular la demanda, ha aumentado las ganancias 
de las empresas donde surge el capital necesario para absorber la fuerza de trabajo desplazada por los cambios en la demanda, sea en la industria o en los servicios.

Por el contrario, la competencia de las importaciones de manufacturas periféricas tiende más bien a realizarse mediante el descenso de los precios. Ello significa entonces disminución de las ganancias y de la capacidad de acumulación de las empresas. El desplazamiento de la demanda y el desempleo no encuentran una respuesta positiva en los centros. La respuesta ha sido negativa mediante aquellas crecientes restricciones aplicadas unilateralmente por los centros, si no en la forma, al menos en el fondo.

Contrasta esta resistencia de Ios centros a recibir importaciones de manufacturas a precios inferiores con su inveterado empeño en procurarse productos primarios en là periferia a los precios más bajos posibles. La explicación es simple: en el primer caso, disminuyen las ganancias de las empresas (su excedente económico); en tanto que en el segundo, ellas aumentan.

Esa respuesta negativa de Ios centros significa un gran menoscabo en las ventajas clásicas del intercambio que tanto habían proclamado los centros en los países periféricos. Los primeros pierden la oportunidad de exportar bienes de alto contenido tecnológico e importar bienes de menor contenido tecnológico, en desmedro tanto de su productividad como de la productividad de la periferia.

La verdad es que a los centros no les conviene la competencia por medio de la baja perturbadora de los precios, ni tampoco a la periferia, que así se desprende de parte del fruto de su progreso técnico. Por ende se comprueba la necesidad de examinar nuevas fórmulas que permitan a los países periféricos participar progresivamente en el crecimiento de consumo de los centros. Nuevas fórmulas que tendrían que insertarse adecuadamente en los mecanismos multilaterales del GATr.

Sería ilusorio pensar que nuestras exportaciones de manufacturas serán suficientes para atender las crecientes necesidades de importación que acompañan al desarrollo, más los servicios de la deuda, por mucho que éstos se alivien. En consecuencia, habrá que acudir ineludiblemente a la sustitución de importaciones, lo cual no podrá hacerse sin una moderada protección. Hay que reconocer que ésta ha sido generalmente exagerada y pocas veces se ha inspirado en claros objetivos de transformación estructural.

Dicho sea de pasada, debido a la tendencia al desequilibrio estructural con los centros, inherente al desarrollo, la protección periférica tiene una significación diferente a la de los centros. Esta última acentúa la tendencia al desequilibrio estructural; en tanto que la protección periférica, dentro de límites racionales, tiende a corregir ese desequilibrio.

Es oportuno subrayar este concepto, pues se olvida con frecuen- 
cia la significación primordial de la polftica de los centros en esta materia. Cuanto menor sea su disposición a recibir importaciones provenientes de la periferia, sea por su más lenta demanda o por el proteccionismo, tanto más obligarán a la periferia a cambiar la composición de sus propias importaciones mediante la protección, a fin de ajustarse a su capacidad de pagos exteriores. Pero este cambio tiene que efectuarse en el marco de mercados más amplios que los nacionales.

\section{EL COMERCIO RECÍPROCO}

Esta última consideración me lleva a subrayar la importancia decisiva del comercio recíproco a fin de llevar a la práctica en la forma más económica posible la substitución de importaciones.

El problema radica principalmente en el intercambio con los centros, pues allí se encuentra sobre todo el origen de la tendencia al desequilibrio estructural. Nuestra demanda de bienes de capital, bienes intermedios y bienes de consumo, en que avanza continuamente la tecnología de los centros, es mucho más intensa de lo que puede costearse con nuestras exportaciones primarias y de manufacturas. Para corregir esta tendencia es indispensable substituir una parte de la demanda exterior de esos bienes desplazándola hacia la producción interna en un marco más amplio que el marco nacional. Se trata de bienes en que ya se dispone de aptitud tecnológica o podría ésta ser accesible gracias a un esfuerzo bien orientado. Al realizar estas substituciones quedaría margen para importar aquellos otros bienes que por su avanzada tecnología no podríamos aún producir internamente, al menos por ahora, o bienes para cuya producción carecemos de recursos naturales.

Es en estas subsituciones en donde debiera concentrarse preferentemente nuestra atención en los próximos años. Habría que realizar arreglos de concertación de la producción, comenzando por dos o más países y extendiendo progresivamente el ámbito de comercio recíproco. Las transnacionales lo están haciendo en sus propias operaciones, y de acuerdo con sus propios intereses. Estos arreglos tendrían que realizarse ahora, en un claro contexto de desarrollo, que tiene que ser determinado por nuestros gobiernos. Creo que las empresas públicas y privadas de buena parte de nuestros países están en condiciones de abordar estos asuntos y llegar también, en los casos en que fuera aconsejable, a combinar esfuerzos con las transnacionales, pero en forma transparente y de acuerdo con nuevas reglas del juego.

La experiencia de arreglos de comercio recíproco entre países latinoamericanos entraña enseñanzas positivas y negativas que es necesario aprovechar ahora. Ante todo, la substitución tiene que tener como punto principal de mira corregir la tendencia al desequi- 
librio exterior de carácter estructural. Además, tiene que procurar que mientras no se consiga reciprocidad entre los países participantes debido en gran parte a diferencias en el grado de avance tecnológico, los países más favorecidos, que serían generalmente los de mayor industrialización, tendrían que vender sus bienes a precios internacionales - gracias a medidas adecuadas - y también tendrían que participar en inversiones destinadas a promover actividades en algunos países para eliminar sus desventajas en el intercambio recíproco. Estos y atros puntos debieran ser materia de preferente atención a la luz de la experiencia pasada.

Desde otro punto de vista, los arregios de intercambio recíproco han sido acaso demasiado ambiciosos. Desde luego, la liberalización del intercambio en las industrias existentes es un objetivo importante. Pero no contribuye a corregir el desequilibrio estructural con los centros. La liberalización tendría que ser también selectiva y progresiva, sobre todo como factor de reciprocidad, según se tiene dicho más arriba.

\section{EL PAPEL DINÁMICO DE LA PERUFERIA}

Las explicaciones que he presentado anteriormente -aunque en forma muy sucinta debido a la indole de este trabajo- me llevan a afirmar que, por primera vez en el desenvolvimiento histórico del capitalismo, la periferia podría desempeñar un creciente papel dinámico en el desarrollo de los centros.

La periferia se había caracterizado por su papel pasivo. En los tiempos pretéritos del desarrollo hacia afuera su ritmo de desarrollo dependía fundamentalmente del ritmo de sus exportaciones primarias a los centros. Después, gracias a su industrialización, pudo acelerar ese ritmo mediante la substitución de importaciones, pero sin adquirir un papel dinámico en relación a los centros. Ahora, sobre la base de la experiencia adquirida en la substitución de importaciones, la periferia ha comenzado a desplegar su aptitud exportadora de manufacturas. Y ello constituye un factor primordial en su papel dinámico.

¿Pero en qué consiste ese papel? La explicación es muy simple. La periferia tiene una ingente demanda potencial de bienes de alto coeficiente tecnológico que las innovaciones de los centros diversifican incesantemente. $\mathrm{Y}$ cuanto más capacidad efectiva tenga para satisfacer esta demanda, adquiriendo exportaciones en los centros, tanto más intenso será este papel dinámico en el desarrollo de aquéllos.

Esto se debe a dos efectos en que se manifiestan las ventajas del intercambio. Por un lado, el intercambio de esos bienes tecnologicamente cada vez más avanzados de los centros con otros menos avanzados de la periferia, contribuirá a elevar en ellos la producti- 
vidad que ha sufrido un intenso menoscabo. Por otro, el mayor empleo que el acrecentamiento de esas exportaciones de los centros traerá aparejado, facilitará la transferencia en ellos de fuerza de trabajo desde las actividades que tienden a crecer con relativa lentitud hacia las que lo hacen con mayor rapidez, dado los continuos cambios. que experimenta la composición de la demanda.

Bien sabemos que es precisamente en las actividades que crecen con relativa lentitud donde inciden las importaciones de manufacturas procedentes de la periferia. En efecto, se trata de bienes que, contrariamente a lo que ocurre en los productos primarios importados desde la periferia, la técnica ha experimentado un proceso de diversificación que le permitiría a esta última abrirse paso en el consumo de los centros, si es que se llega a nuevas fórmulas de intercambio. Y cuanto más se acrecienten en los centros las exportaciones de bienes de alto coeficiente tecnológico, tanto más contribuirán a facilitar los desplazamientos de fuerza de trabajo provocados por la competencia periférica en bienes de menor coeficiente tecnológico, pero también con crecientes posibilidades de diversificación y más amplios mercados.

Este problema debe encararse desde un punto de vista eminentemente dinámico. La periferia necesita acelerar su ritmo de desarrollo si ha de absorber con creciente productividad el incremento de su fuerza de trabajo, junto a la que ha quedado relegada en el fondo de la estructura social. En esas circunstancias, la demanda de importaciones provenientes de los centros tendería a crecer con fuerte ritmo. En tanto este ritmo, como es muy probable, tienda a exceder la capacidad de pago generada por las importaciones de los centros, habrá que sustituir importaciones en la periferia en mercados más amplios que los nacionales, a fin de lograr una producción sustitutiva más económica.

Ahora bien, dado el ritmo de desarrollo que un país periférico se proponga alcanzar, la medida en que deba sustituir dependerá del grado de receptividad de los centros en función de su ritmo de desarrollo, así como del grado de apertura, de su participación en el crecimiento del consumo de los centros $y$, eventualmente, de su propio consumo.

Se llega así a la importante conclusión de que el papel dinámico de la periferia, por grande que sea su potencialidad, dependerá a su vez de la dinámica de los centros. Existiría, pues, una interdependencia dinámica en esta nueva etapa de las relaciones centroperiferia.

Para que esta interdependencia se cumpla con eficacia, es indispensable que el desenvolvimiento previo de las exportaciones de los centros a la periferia genere un aumento de empleo que facilite el desplazamiento de fuerza de trabajo de las actividades en que incide la competencia periférica. Este impulso inicial depende en 
gran parte de que la periferia disponga de recursos financieros externos que le permitan cubrir parte de las importaciones de bienes requeridas por su desarrollo. El desplazamiento y absorción de fuerza de trabajo será una consecuencia de ello, pero no podría preceder al acrecentamiento de exportaciones.

Para terminar este aspecto, creo que el papel dinámico de la periferia podría adquirir una profunda significación. Hasta ahora los centros sólo se han interesado en el desarrollo de la periferia en la forma y medida en que convenía a sus intereses, salvo episodios circunstanciales y transitorios. No les ha interesado el desarrollo periférico en profundidad social, esto es, destinado a elevar persistentemente la productividad y el ingreso de grandes masas de la población. Se opusieron primero a la substitución de importaciones y después al intercambio recíproco, salvo en cuanto representan ventajas para las transnacionales, aunque no necesariamente para el desarrollo periférico.

Si una política de cooperación alienta el papel dinámico de la periferia, podría cambiar fundamentalmente este estado de cosas. He ahí una esperanza que pudiera alentar la próxima reunión de UNCTAD.

\section{UNGTAD Y EL NUEVO ORDEN ECONÓMICO INTERNAGIONAL}

Prevalece el pesimismo acerca de que pueda avanzarse en la consideración del nuevo orden económico internacional. Pero este pesimismo no debiera dominar las deliberaciones. Por el contrario, el receso que afecta a la vez a los centros, a los países periféricos y a los socialistas, contribuye a que UNGTAD sea el ámbito apropiado para considerar el problema inmediato e inaplazable de la recuperación mundial, abriendo esas nuevas perspectivas de interdependencia dinámica.

Hay que afirmar con gran vigor y confianza las posibilidades concretas de iniciar e impulsar este proceso en favor de todos. Existen, sin duda alguna, las bases para hacerlo. Pero la adhesión pertinaz a ideas y formas de acción convencionales está sofocando estas posibilidades. Esas ideas han quedado a la zaga del enorme adelanto científico de otras disciplinas. Es necesario innovar también en materia económica, pues tales formas de acción perjudican a toda la economía mundial. Se está desmoronando lo mucho que se había conseguido después de la Segunda Guerra Mundial.

Ha llegado el momento de lanzar nuevas ideas y formular nuevas formas de acción que respondan a la extraordinaria convergencia de intereses acerca de la necesidad de una política de recuperación que debiera iniciarse sin preocupantes demoras. Es necesario que nuestros países, conjugados con el resto de la periferia, hagan ofr su voz, voz que es cada vez más potente en los mismos centros.

Sólo la recuperación de los países desarrollados permitirá vencer 
el proteccionismo y el riesgo inminente de fraccionamiento económico entre ellos, con la correspondiente exacerbación de conflictos. $\mathrm{Y}$ aliviará los grandes obstáculos que se oponen a la política de recuperación en la periferia, tan afectada por ese proteccionismo de los centros. A medida que avance la recuperación de éstos, podrán evitarse nuevas medidas que entorpezcan las importaciones provenientes de la periferia y comenzar el camino hacia medidas estructurales de liberalización. El avance de la recuperación de los centros irá aliviando asimismo el deterioro de la relación de intercambio de los países periféricos. Mientras tanto, el reajuste fundamental de las deudas y la cooperación financiera serán de gran significación para unos y otros, pues la mayor capacidad de pagos exteriores de nuestros países y el resto de los países en desarrollo permitirá satisfacer las necesidades de importación inherentes a la recuperación de la periferia (y su ulterior desarrollo), lo cual podría contribuir notablemente a la recuperación de los mismos centros, según se ha explicado anteriormente.

En fin, es evidente una clara vinculación de intereses recíprocos que debieran subrayarse en la sexta reunión de la UNCTAD. Y así podría llegarse a la oportuna consideráción del nuevo orden económico mundial, que supone, fundamentalmente, grandes cambios estructurales. Lo coyuntural, sin embargo, debiera merecer un alto orden de prelación. Primero lo coyuntural, para abrir paso a medidas estructurales de gran envergadura. 